\title{
Effect of Supercharging\& Injection Pressure on Engine Emission Characteristic of Jetropha Biodiesel Blend.
}

\author{
Harsh G Chaudhari ${ }^{1}$, Dr. Tushar M Patel ${ }^{2}$, Prof. Pragna R Patel ${ }^{3}$ \\ ${ }^{1 *}$ M.E. Scholar, Mechanical Engineering Department, LDRP-ITR, Gandhinagar, Gujarat, India. \\ ${ }^{2}$ Professor, Mechanical Engineering Department, LDRP-ITR, Gandhinagar, Gujarat, India. \\ ${ }^{3}$ Assistant Professor, Mechanical Engineering Department, LDRP-ITR, Gandhinagar, Gujarat, India.
}

\begin{abstract}
Jatrophacurcas as a non-edible methyl ester biodiesel fuel source is utilized to run single cylinder, variable compression ratio and four-stroke diesel engine. Emission parameters are measured for Jatropha biodiesel - diesel mixes. The properties of fuel biodiesel for example kinematic viscosity, calorific value, flash point, carbon deposit and specific gravity were found. Tests have been conducted using the biodiesel blends of 100DOB, 50D50B, OD100B where diesel is denoted by D and Jatropha biodiesel is denoted by B.The emission parameters are additionally influenced by different working parameters like inlet air pressure, injection pressure and compression ratio. The paper deals with effects on engine fueled with diesel, mix of diesel with biodiesel and simply on biodiesel with a view to give a stage to the correlation of the emission parameter. The variation of $\mathrm{CO}, \mathrm{HC}, \mathrm{CO}_{2}$ and NOx emissions with different load of the engine at different injection pressure for fuel D0B100 (Jatropha bio diesel), D50B50 (Blended Jatropha) \& D0B100 (Jatropha biodiesel) of the engine normal \& supercharging condition is studied \& concluded. In result found that with supercharging condition Jatropha biodiesel DOB100 have considerable lesser Emission of $\mathrm{HC}, \mathrm{CO}_{2}, \mathrm{NO}_{X}$ as compared to D50B50. D50B50 Jatropha blend has a lowest CO emission at all loading conditions than DOB100 and diesel fuel at the engine supercharging condition.HC emission of diesel engine is low with the use of DOB100 fuel of medium injection pressure \& with the engine supercharging condition compare to D50B50.
\end{abstract}

Keyword: Diesel Engine, Jatropha biodiesel, Biofuels, Blending, Emission Characteristic, Supercharging, Injection Pressure, Inlet Air pressure.

\section{Introduction}

The constant increment in the rate of utilization of the fossil fuels, depend upon the regularly increasing in population and the urbanization in the present day world has made the consumption of these ordinary fuel resources in the near future a very unavoidable truth. Also, the greenhouse gas outflows from these fossil fuels are continually degrading the planet and bringing about an earth wide temperature increase and other environmental related issues. Thusly, the circumstance requests for a substitute alternate source of energy that can be utilized to overcome the forecasted future energy emergency. Notwithstanding this, if the energy source is clean and renewable it will lessen the natural issues too. During this mission for a substitute and renewable energy sources, researchers have found that biodiesel-diesel mixes as option fuels has turned into a famous alternative fuels. This is because researchers have seen that the properties of biodiesel prepared from vegetable oils are near to pure diesel and in this way it has a promising future as an optional fuel for diesel engine [2]. Biodiesel is as an optional fuel got from vegetable (green) oil or animal fats are oxygenated, bio de-gradable, non-harmful and earth safe. Biodiesel's are classified into two categories as eatable and non-eatable. Eatable oils are such that sunflower, corn, rapeseed, palm, and soybean and waste vegetable oils. The non-eatable oils are such that Jatropha, Karanja, Polanga oils and likes [3]. Expanding sympathy toward ecological contamination alongside keeping up performance of diesel engines has prompted broad research in the area of fuel. Among different choices researched for diesel fuel, biodiesel has ended up being most reasonable for diesel engines [5]. Different research works have proved that performance of biodiesel is almost like diesel engines with less discharges. Further engine parameters, for example compression ratio, injection timing and injection pressure are likewise observed to be significant factors contributing on the performance and emission parameter of diesel engine fueled with biodiesel. Present paper focuses on effect of parameter viz.inlet air pressure and injection pressure.In its practicaltwo different conditions for finding the best result of C.I. Engine using Jatropha biodiesel.(1) Normal condition (2) Supercharging condition. The paper provides a platform for comparison of effect of varying load on emission characteristic of engine fueled by (a) 100\% diesel (b) Blend of diesel \& Biodiesel (c) 100\% Biodiesel [6].

\section{Literature Review}

Chaudhari et al (2016) they researched on the performance of small capacity compression ignition engine using Jatropha biodiesel blends. In their experiment engine was run at default set compression ratio of 17.5 and 
injection pressure of 180 bar. Performance was measured at three different loading condition for each blends used in investigation. It was found that at lower blends performance is similar to that of diesel fuel. Highest thermal efficiency was found for B20 v/v blend, which was 26.43\% while other blend B30 shown similar thermal efficiency compare to diesel but was lower than B20.They concluded that lower blend ratio of biodiesel can be successfully used for diesel engine without modification. [16].Paula \&Datta et al (2013) they considered on exploratory and numerical examination of the execution, ignition and discharge characteristics of a diesel engine filled with Jatropha biodiesel. The execution qualities demonstrates that brake particular fuel utilization (BSFC) increments and brake warm effectiveness diminishes with the utilization of Jatropha biodiesel. Burning characteristics demonstrate an expansion in pinnacle chamber weight and a reduction in start defer period with the increment in biodiesel partake in the mixes; while the discharge of $\mathrm{NOx}$ and $\mathrm{CO}_{2}$ builds smoke [12].Rajneesh Kumar et al (2012) they considered on discharge and performance attributes of Jatropha ethyl ester mixes with diesel fuel in a diesel Engine. They observed that brake particular fuel utilization expanded with increment in centralization of mixes in diesel fuel. NOx outflows expanded with increment in rate of ester in mix when contrasted with diesel fuel furthermore expanded with increment in load.CO discharges were lower for every one of the mixes at all heaps. CI engine could be worked without influencing the performance of the engine with $40 \%$ mixing of Jatropha ethyl ester biodiesel with diesel [13].

After observing literature review we concluded that, to find out the other option like alternative fuel that can be used and get energy from it. For higher performance, engine must be modified. When alternative fuel is used as a blend with diesel than there must have to do optimization of parameter which one directly or indirectly effect on the emission of the engine.From above survey, researcher took Jatropha fuel as a blend and optimize one parameter which affect the emission characteristics of the engine. The emission characteristics have been analyzed and compared to baseline diesel fuel.

\section{Jatropha Oil}

The performance and emission characteristics of biodiesel fueled engine depend purely upon the thermo physical properties of the biodiesel. Since Jatropha oil can be grown in wastelands, its cultivation to biodiesel production can also generate a large scale employment in a country like India. Basically the biodiesels are derived from vegetable oils via a popular process, transesterification in the presence of a catalyst and alcohol as a reactant.[2] Due to the availability and cost factor methyl alcohol is commonly used and the derived biodiesel is also known as fatty acid methyl ester. The purpose of the transesterification process is to lower the viscosity of the oil [15].

Table 3.1 Comparison of property Jatropha biodiesel vs Diesel [11]

\begin{tabular}{|l|l|l|l|}
\hline Sr. no. & Properties & Jatropha biodiesel & Diesel \\
\hline 1 & Colour & Golden yellow & Orange \\
\hline 2 & Mass fraction $(\%)$ & & \\
\hline & Carbon & 0.766 & 0.87 \\
\hline & Hydrogen & 0.121 & 0.126 \\
\hline & Oxygen & 0.113 & 0.004 \\
\hline 3 & Density at $323 \mathrm{~K}\left(\mathrm{~kg} / \mathrm{m}^{3}\right)$ & 862 & 830 \\
\hline 4 & Specific gravity at $30^{\circ} \mathrm{C}$ & 0.886 & 0.84 to 0.88 \\
\hline 5 & Gross calorific value $(\mathrm{Mj} / \mathrm{Kg})$ & 41 & 42 \\
\hline 6 & Kinematic viscosity, $\mathrm{Cst} @ 40^{0} \mathrm{C}$ & 4.20 & 2 \\
\hline 7 & Cetane number & $57-62$ & 55 \\
\hline 8 & Boiling point ${ }^{0} \mathrm{C}$ & 286 & 248 \\
\hline 9 & Solidifying point ${ }^{\circ} \mathrm{C}$ & -10 & -14 \\
\hline 10 & Molecular mass & 282 & 190 \\
\hline
\end{tabular}

\section{Experimental Setup And Method}

\subsection{Experimental Setup}

The setup consists of single cylinder, four stroke, multi-fuel, research engine connected to eddy type dynamometer for loading. The operation mode of the engine can be changed from diesel to Petrol and from Petrol to Diesel with some necessary changes. In both modes the compression ration can be varied without stopping the engine and without altering the combustion chamber geometry by specially designed tilting cylinder block arrangement. The injection point and spark point can be changed for research tests. Setup is provided with necessary instruments for combustion pressure, Diesel line pressure and crank-angle measurements [19]. These signals are interfaced with computer for pressure crank-angle diagrams. Instruments are provided to interface airflow, fuel flow, temperatures and load measurements. The setup has stand-alone panel box consisting of air box, two fuel flow measurements, process indicator and hardware interface. Rota meters are provided for cooling water and calorimeter water flow measurement. A battery, starter and battery charger is provided for engine electric start arrangement [18]. 
The setup enables study of VCR engine performance for brake power, indicated power, frictional power, BMEP, IMEP, brake thermal efficiency, indicated thermal efficiency, Mechanical efficiency, volumetric efficiency, specific fuel consumption, $\mathrm{A} / \mathrm{F}$ ratio, heat balance and combustion analysis. Lab view based Engine Performance Analysis software package "Engine soft" is provided for on line performance evaluation [17].

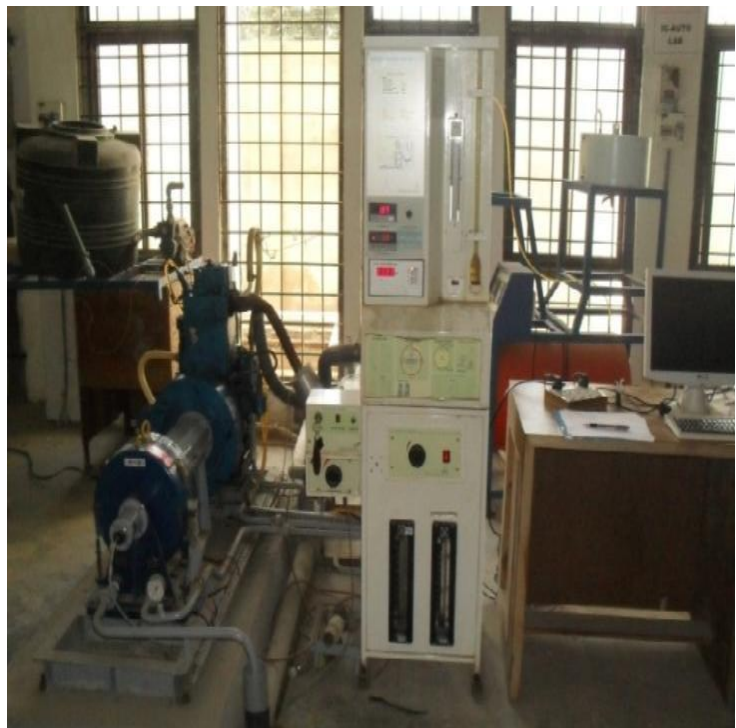

Fig 4.1.1 Front view of experimental setup

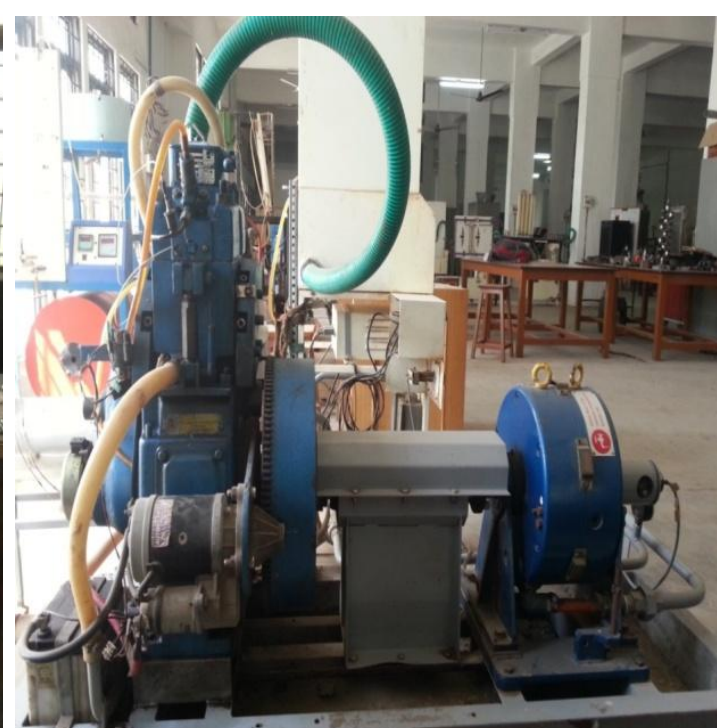

Fig 4.1.2 Side view of experimental setup

Table 4.1 Technical specifications [16]

\begin{tabular}{|l|l|}
\hline Engine manufacturer & Apex Innovations (Research Engine test set up) \\
\hline Software & Engine soft Engine performance analysis software \\
\hline Engine type & Single cylinder four stroke multi fuel research engine \\
\hline No. of cylinder & 1 \\
\hline Type of cooling & Water cooled \\
\hline Rated Power & $3.5 \mathrm{~kW} \mathrm{@} 1500 \mathrm{rpm}$ \\
\hline Cylinder diameter & $87.5 \mathrm{~mm}$ \\
\hline Orifice diameter & $20 \mathrm{~mm}$ \\
\hline Stroke length & $110 \mathrm{~mm}$ \\
\hline Connecting rod length & $234 \mathrm{~mm}$ \\
\hline Dynamometer & Type: eddy current, water cooled, with loading unit \\
\hline
\end{tabular}

\subsection{Experimental Methodology}

In this experiment, diesel engine is used and connected with the rope break dynamometer, with the help of dynamometer, vary the load on the engine or remain constant .Gas analyzer is used to find the emission characteristic of exhaust gas. The reading takes by constant load or by varying the load on the engine using the dynamometer. Engine performance such as break power, indicated power, break specific fuel consumption etc. are found from the experiments.

First of all experimental set up is developed to fulfil the objective and it contains single cylinder diesel engine. Inlet air pressure \& injection pressure are taken for the optimization for same compression ratio at different load. We used two different condition for finding the best result of C.I. Engine using Jatropha biodiesel. [1] Normal condition- In its first condition engine take atmospheric air as an inlet air. [2] Supercharging condition- In it engine take continuous flow of air with the use of air compressor as an external device.Take the Measurement using pure diesel, blended diesel \& bio-diesel fuel at different load condition, different injection pressure for the two condition \& measure the performance and emission of C.I. Engine. Emission reading is also taken by gas analyser equipment for emission analysis purpose. 


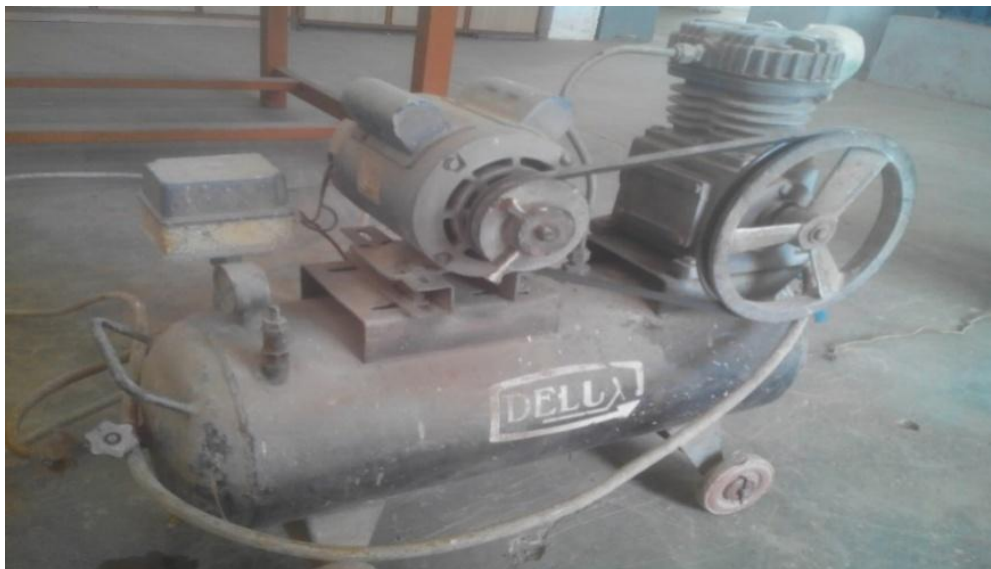

Fig 4.2.1 Air compressor

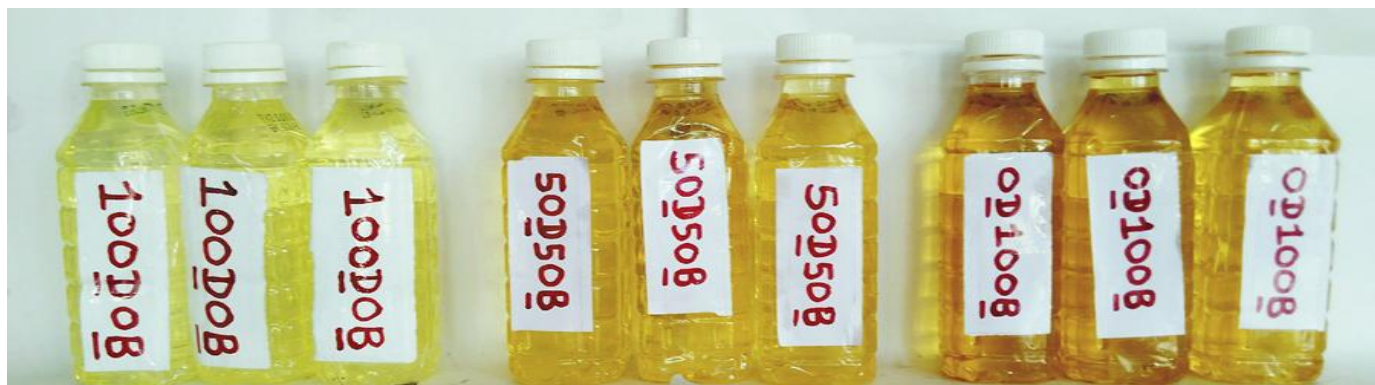

Fig 4.2.2 Diesel, Blended Fuel \&Jatropha bio oil

\section{Result \& Discussion}

At the end of the experiment final data collected easily by the ICEngine soft. Directly.Observation table \& graph of emission analysis is as discussed below.

\subsection{Engine emission data using engine normal condition:}

Table 5.1 Different blends emission data with engine normal condition of engine

\begin{tabular}{|c|c|c|c|c|c|c|c|c|}
\hline Ex. No & Blend Ratio & $\begin{array}{l}\text { Injection } \\
\text { Pressure }\end{array}$ & $\begin{array}{l}\text { Load } \\
\text { (kg) }\end{array}$ & CO (\%) & HC(ppm) & $\mathrm{CO}_{2}(\%)$ & $\mathrm{O}_{2} \quad(\%)$ & $\mathrm{NO}_{\mathbf{X}}(\mathbf{p p m})$ \\
\hline 1 & D100B0 & $\mathrm{L}$ & 1.02 & 0.05 & 26 & 1 & 19.27 & 137 \\
\hline 2 & D100B0 & $\mathrm{L}$ & 5.02 & 0.04 & 20 & 1.4 & 18.56 & 333 \\
\hline 3 & D100B0 & $\mathrm{L}$ & 8.89 & 0.02 & 48 & 1.8 & 17.98 & 830 \\
\hline 4 & D100B0 & $\mathrm{M}$ & 1.02 & 0.06 & 23 & 1 & 19.23 & 119 \\
\hline 5 & D100B0 & $\mathrm{M}$ & 5.01 & 0.03 & 32 & 1.3 & 18.66 & 339 \\
\hline 6 & D100B0 & $\mathrm{M}$ & 8.98 & 0.02 & 49 & 1.8 & 18 & 795 \\
\hline 7 & D100B0 & $\mathrm{H}$ & 1 & 0.07 & 10 & 0.9 & 19.28 & 88 \\
\hline 8 & D100B0 & $\mathrm{H}$ & 4.92 & 0.03 & 27 & 1.3 & 18.66 & 321 \\
\hline 9 & D100B0 & $\mathrm{H}$ & 8.97 & 0.03 & 45 & 1.8 & 17.98 & 769 \\
\hline 10 & D50B50 & $\mathrm{L}$ & 0.99 & 0.07 & 9 & 1 & 18.96 & 99 \\
\hline 11 & D50B50 & $\mathrm{L}$ & 5.01 & 0.05 & 33 & 1.6 & 18.21 & 315 \\
\hline 12 & D50B50 & $\mathrm{L}$ & 8.79 & 0.04 & 28 & 1.4 & 18.37 & 315 \\
\hline 13 & D50B50 & $\mathrm{M}$ & 0.98 & 0.08 & 20 & 1.1 & 18.89 & 80 \\
\hline 14 & D50B50 & $M$ & 4.99 & 0.05 & 33 & 1.6 & 18.21 & 299 \\
\hline 15 & D50B50 & $M$ & 8.33 & 0.04 & 33 & 2 & 17.42 & 657 \\
\hline 16 & D50B50 & $\mathrm{H}$ & 0.97 & 0.08 & 24 & 1 & 19.04 & 62 \\
\hline 17 & D50B50 & $\mathrm{H}$ & 4.96 & 0.05 & 37 & 1.6 & 18.25 & 276 \\
\hline 18 & D50B50 & $\mathrm{H}$ & 8.86 & 0.04 & 47 & 1.9 & 17.52 & 645 \\
\hline 19 & D0B100 & $\mathrm{L}$ & 0.95 & 0.08 & 53 & 1.1 & 19.03 & 39 \\
\hline 20 & D0B100 & $\mathrm{L}$ & 5.07 & 0.04 & 17 & 1.5 & 18.29 & 283 \\
\hline 21 & D0B100 & $\mathrm{L}$ & 8.95 & 0.03 & 19 & 1.9 & 17.72 & 589 \\
\hline 22 & D0B100 & $\mathrm{M}$ & 0.97 & 0.08 & 18 & 1 & 19.03 & 72 \\
\hline 23 & D0B100 & $M$ & 5.01 & 0.04 & 18 & 1.5 & 18.3 & 260 \\
\hline 24 & D0B100 & $\mathrm{M}$ & 8.86 & 0.03 & 26 & 1.8 & 17.69 & 564 \\
\hline 25 & D0B100 & $\mathrm{H}$ & 0.96 & 0.09 & 19 & 1 & 19.06 & 48 \\
\hline 26 & D0B100 & $\mathrm{H}$ & 5 & 0.04 & 1 & 1.5 & 18.46 & 219 \\
\hline 27 & D0B100 & $\mathrm{H}$ & 8.78 & 0.03 & 35 & 1.8 & 17.69 & 537 \\
\hline
\end{tabular}




\subsection{Engine emission data using engine supercharging condition}

Table 5.2 Different blends emission data with engine supercharging condition

\begin{tabular}{|c|c|c|c|c|c|c|c|c|}
\hline Ex. No & Blend Ratio & $\begin{array}{l}\text { Injection } \\
\text { Pressure }\end{array}$ & Load (kg) & $\mathrm{CO}(\%)$ & HC (ppm) & $\mathrm{CO}_{2}(\%)$ & $\mathrm{O}_{2} \quad(\%)$ & $\mathrm{NO}_{\mathbf{x}}(\mathrm{ppm})$ \\
\hline 1 & D100B0 & $\mathrm{L}$ & 1.02 & 0.05 & 22 & 1 & 18.98 & 145 \\
\hline 2 & D100B0 & $\mathrm{L}$ & 5.02 & 0.03 & 30 & 1.6 & 18.05 & 500 \\
\hline 3 & D100B0 & $\mathrm{L}$ & 8.89 & 0.03 & 31 & 2 & 17.28 & 920 \\
\hline 4 & D100B0 & $\mathrm{M}$ & 1.02 & 0.05 & 26 & 1.2 & 18.79 & 176 \\
\hline 5 & D100B0 & $\mathrm{M}$ & 5.01 & 0.04 & 22 & 1.6 & 18.05 & 500 \\
\hline 6 & D100B0 & $\mathrm{M}$ & 8.98 & 0.03 & 31 & 2 & 17.27 & 948 \\
\hline 7 & D100B0 & $\mathrm{H}$ & 1 & 0.06 & 27 & 1.1 & 18.85 & 156 \\
\hline 8 & D100B0 & $\mathrm{H}$ & 4.92 & 0.04 & 26 & 1.7 & 17.91 & 493 \\
\hline 9 & D100B0 & $\mathrm{H}$ & 8.97 & 0.03 & 37 & 2 & 17.32 & 942 \\
\hline 10 & D50B50 & $\mathrm{L}$ & 0.99 & 0.07 & 56 & 1.1 & 18.76 & 170 \\
\hline 11 & D50B50 & $\mathrm{L}$ & 5.01 & 0.04 & 54 & 1.6 & 17.93 & 539 \\
\hline 12 & D50B50 & $\mathrm{L}$ & 8.79 & 0.03 & 24 & 2 & 17.49 & 989 \\
\hline 13 & D50B50 & $\mathrm{M}$ & 0.98 & 0.08 & 23 & 1.1 & 18.89 & 103 \\
\hline 14 & D50B50 & $\mathrm{M}$ & 4.99 & 0.04 & 51 & 1.5 & 18.08 & 417 \\
\hline 15 & D50B50 & $\mathrm{M}$ & 8.33 & 0.03 & 41 & 200 & 17.33 & 1037 \\
\hline 16 & D50B50 & $\mathrm{H}$ & 0.97 & 0.08 & 23 & 1.1 & 18.93 & 84 \\
\hline 17 & D50B50 & $\mathrm{H}$ & 4.96 & 0.04 & 54 & 1.6 & 17.94 & 426 \\
\hline 18 & D50B50 & $\mathrm{H}$ & 8.86 & 0.03 & 50 & 200 & 17.27 & 1032 \\
\hline 19 & D0B100 & $\mathrm{L}$ & 0.95 & 0.09 & 42 & 1.1 & 18.73 & 66 \\
\hline 20 & D0B100 & $\mathrm{L}$ & 5.07 & 0.05 & 38 & 1.6 & 17.98 & 412 \\
\hline 21 & D0B100 & $\mathrm{L}$ & 8.95 & 0.04 & 18 & 2 & 17.69 & 880 \\
\hline 22 & D0B100 & $\mathrm{M}$ & 0.97 & 0.09 & 41 & 1 & 18.8 & 48 \\
\hline 23 & D0B100 & $\mathrm{M}$ & 5.01 & 0.05 & 42 & 1.6 & 17.96 & 331 \\
\hline 24 & D0B100 & $\mathrm{M}$ & 8.86 & 0.04 & 18 & 2 & 17.69 & 880 \\
\hline 25 & D0B100 & $\mathrm{H}$ & 0.96 & 0.09 & 39 & 1 & 18.82 & 38 \\
\hline 26 & D0B100 & $\mathrm{H}$ & 5 & 0.06 & 47 & 1.6 & 17.95 & 288 \\
\hline 27 & D0B100 & $\mathrm{H}$ & 8.78 & 0.04 & 26 & 2 & 17.48 & 754 \\
\hline
\end{tabular}

An alternative fuel used in engines is always evaluated on the basis of both engine performances and its environmental impacts. As such, various parameters defining the performance and emissions of diesel engine which have been evaluated both experimentally and numerically in this work and have been discussed and analyzed in this section.Energy sources being considered diesel, biodiesel for the purpose of present work. After the engine reached the stabilized working condition fuel consumption, air consumption, engine load and exhaust emissions were measured. Engine power for diesel was $5.2 \mathrm{~kW}$ when engine speed was at $1500 \mathrm{rpm}$. In this section, the simulated results are verified with experimental results at the same operating conditions. The validation is done with three extreme fuels, namely pure Jatropha biodiesel (D0B100) Blended Jatropha biodiesel (D50B50) and mineral Diesel (D100B0). In this paper mainly emission parameters are considered at different injection pressure and different load condition with different blends.

\section{A.Exhaust gaseous emissions.}

$\mathrm{CO}, \mathrm{HC}, \mathrm{CO}_{2}$ and $\mathrm{NOx}$ emissions are measured in this study.

\subsection{CO Emission:}

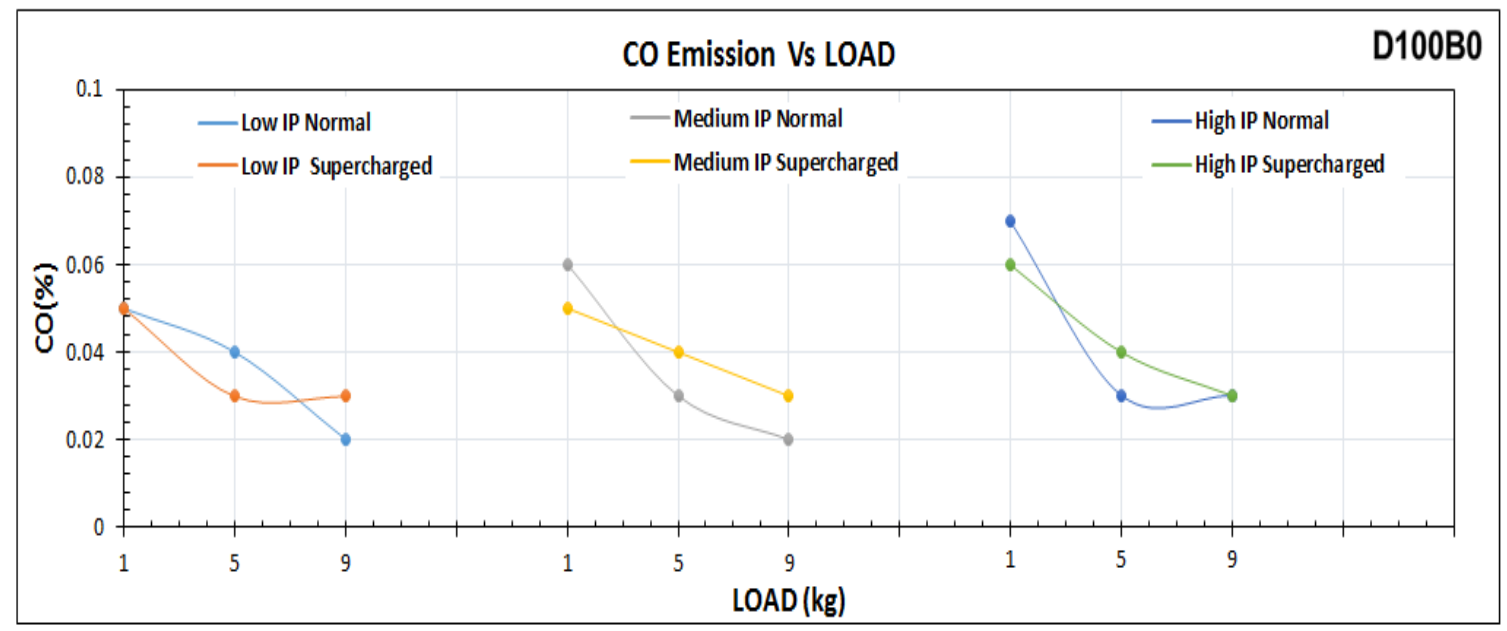

Fig. 5.3.1 CO Emission Vs Load graph for D100B0 
The variation of Carbon monoxide (CO) emission with different load of the engine for fuel D100B0 (pure diesel) of the engine normal \& supercharging condition at different injection pressure is shown in figure 5.3.1. Carbon monoxide (CO) emission decreased with increase in load on the engine for both condition of the engine. In it at low injection pressure normal \& supercharged both condition same $\mathrm{CO}$ emission in 1 load condition \& in load 9 CO emission increased with supercharging effect. In medium injection pressure at load 1 $\mathrm{CO}$ emission is more than supercharged condition \& at load $9 \mathrm{CO}$ emission increased with supercharging effect. In high injection pressure at load $1 \mathrm{CO}$ emission is more in normal condition than supercharged condition $\&$ at load $9 \mathrm{CO}$ emission is same for both condition. So in normal engine running condition $\mathrm{CO}$ emission continuously increasing for diesel as the fuel injection pressure is increased from 140,170 and $200 \mathrm{kgf} / \mathrm{cm}^{2}$ in step for all load conditions. While as in engine running at supercharging condition $\mathrm{CO}$ emission increasingbut not so much as normal engine running condition for diesel as the fuel injection pressure is increased from low $\left(140 \mathrm{kgf} / \mathrm{cm}^{2}\right)$, medium $\left(170 \mathrm{kgf} / \mathrm{cm}^{2}\right)$ and high $\left(200 \mathrm{kgf} / \mathrm{cm}^{2}\right)$ in step for all load conditions.

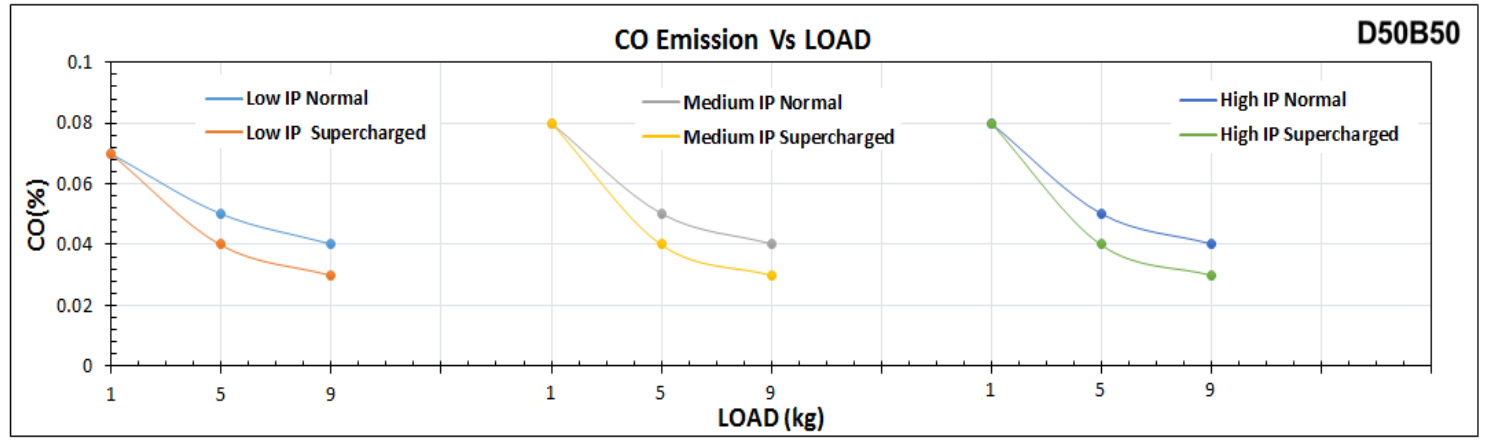

Fig. 5.3.2 CO Emission Vs Load graph for D50B50

The variation of Carbon monoxide (CO) emission with different load of the engine for fuel D50B50 (blended Jatropha bio oil) of the engine normal \& supercharging condition at different injection pressure is shown in figure 5.3.2. Carbon monoxide (CO) emission decreased with increase in load on the engine for both condition of the engine same as D100B0 fuel. From the graph it is clearly seen that for low ,medium \& high injection pressure for all load condition $\mathrm{CO}$ emission decreasing in supercharging condition of engine .

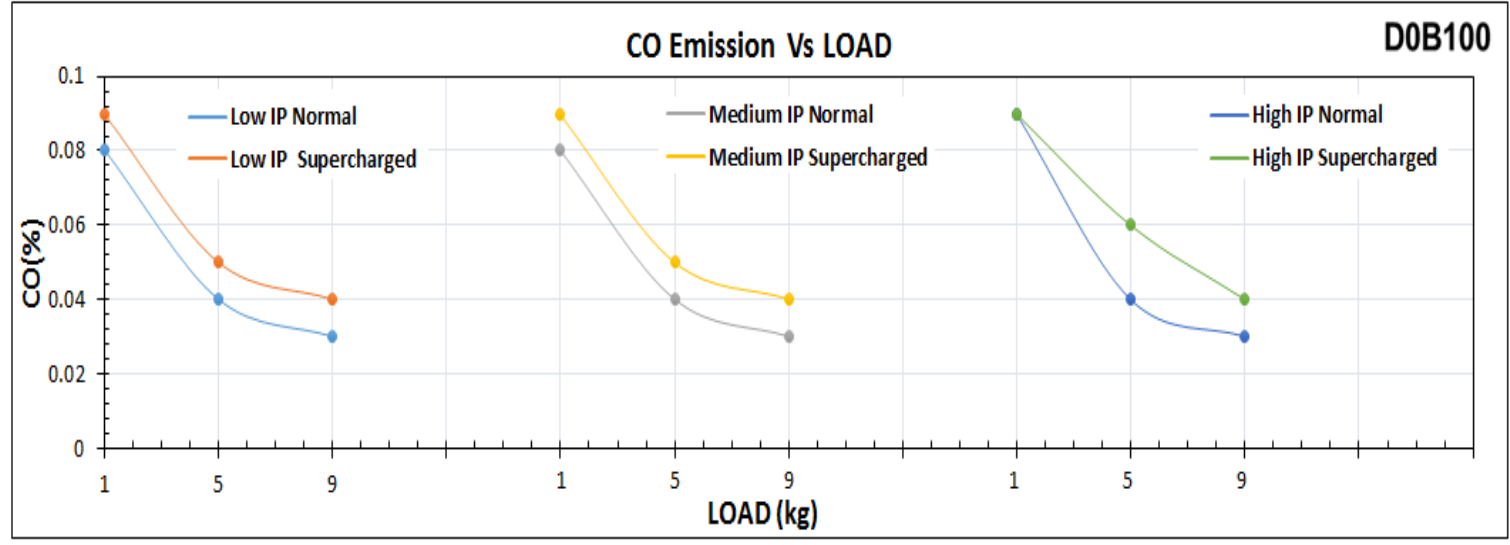

Fig. 5.3.3CO Emission Vs Load graph for D0B100

The variation of Carbon monoxide (CO) emission with different load of the engine for fuel D0B100 (Jatropha bio diesel) of the engine normal \& supercharging condition at different injection pressure is shown in figure 5.3.3. Carbon monoxide (CO) emission decreased with increase in load on the engine for both condition of the engine same as D100B0 \& D50B50 fuel. As shown in graph in all three injection pressure for all load condition $\mathrm{CO}$ emission is high with supercharging effect. So for In D50B50 with supercharging effect CO emission is decreasing than pure Jatropha bio diesel fuel. It was also observed that carbon monoxide emission decreased with Jatropha blend \& pure Jatropha bio diesel fuel with the use of supercharging effect.

\subsection{HC Emission:}

The variations of HCemission with load under various blends \& under various condition of engine are shown in figure. 


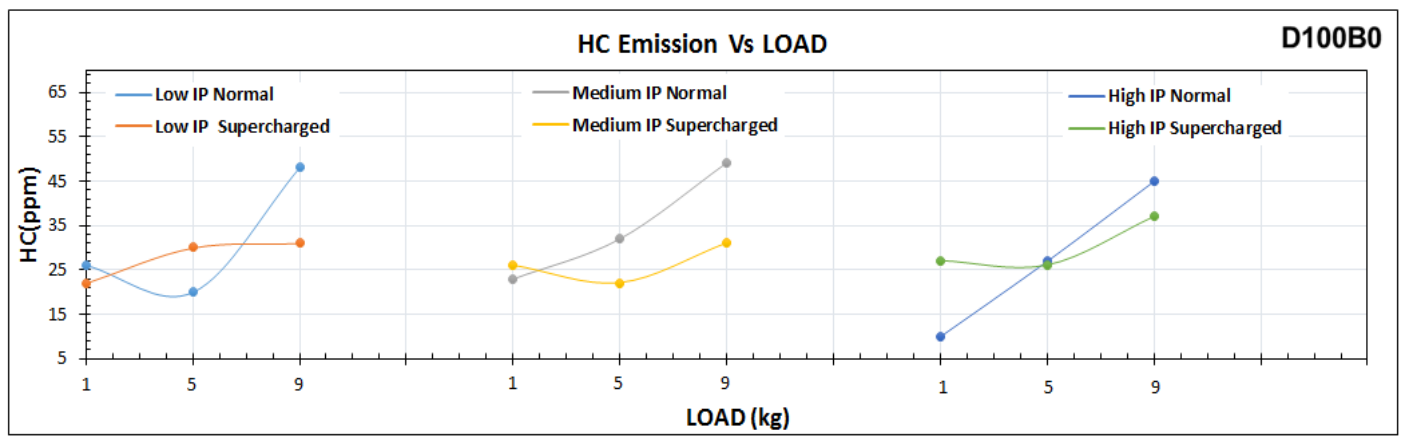

Fig.5.4.1HC Emission Vs Load graph for D100B0

The variation of Hydrocarbon (HC) emission with different load on the engine for fuel D100B0 (pure diesel) of the engine normal \& supercharging condition at different injection pressure is shown in figure 5.4.1. $\mathrm{HC}$ emission increased with increase in load on the engine for both condition of the engine. It was observed that there was no significant difference measured for diesel as the fuel injection pressure is increased from low too high in step for all load conditions. It was also observed that HC emission decreased in supercharged condition.

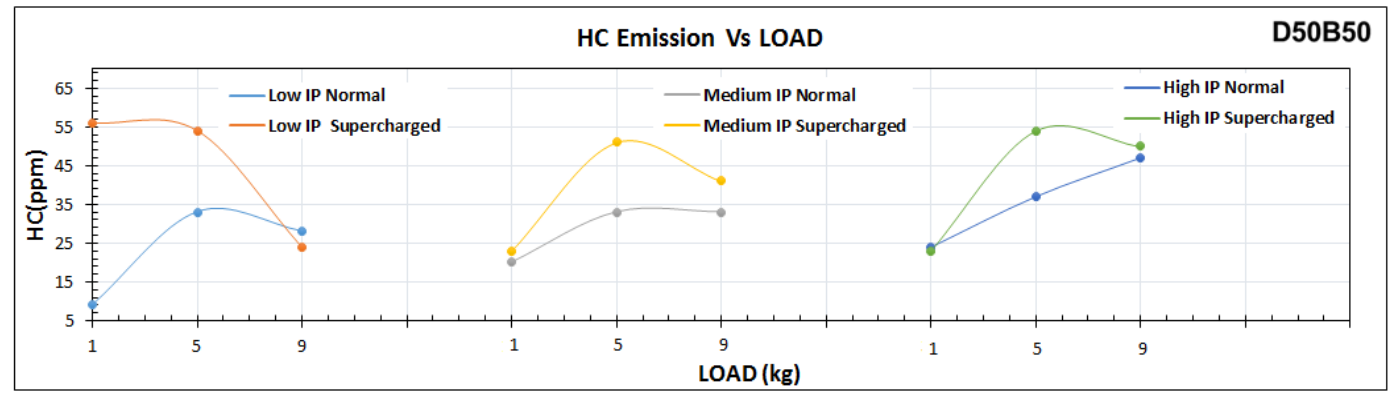

Fig. 5.4.2 HC Emission Vs Load graph for D50B50

The variation of Hydrocarbon (HC) emission with different load on the engine for fuel D50B50 (blended Jatropha) of the engine normal \& supercharging condition at different injection pressure is shown in figure 5.4.2. $\mathrm{HC}$ emission increased with increase in load on the engine for both condition of the engine. It was observed that there was increasing in $\mathrm{HC}$ emission as injection pressure is increased from low too high in step for all load conditions. It was also observed that $\mathrm{HC}$ emission is increased in supercharged condition.

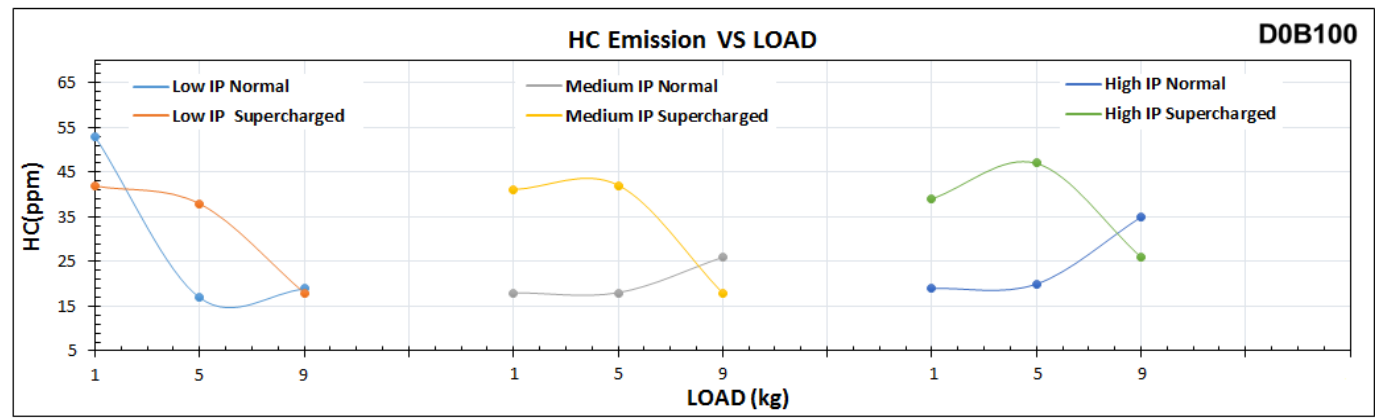

Fig 5.4.3 HC Emission Vs Load graph for D0B100

The variation of Hydrocarbon (HC) emission with different load on the engine for fuel D0B100 (Jatropha bio diesel) of the engine normal \& supercharging condition at different injection pressure is shown in figure 5.4.3. HC emission decreasing with increase in load on the engine for supercharged condition of the engine. While $\mathrm{HC}$ emission increasing with increase in load on the engine for normal condition of the engine. It was observed that there was increasing in $\mathrm{HC}$ emission as injection pressure is increased from low too high in step for all load conditions. It was also observed that $\mathrm{HC}$ emission increased in supercharged condition. So for all fuels only $100 \%$ diesel fuel there is reduction in $\mathrm{HC}$ emission in supercharging condition compare to normal condition.It was also observed that $\mathrm{HC}$ emission decreased with increase in percentage of easters in the fuel when engine run at normal condition only.From the graph it is clear that in D0B100 at medium injection pressure is good for low emission of HC. 


\section{5. $\mathrm{CO}_{2}$ Emission:}

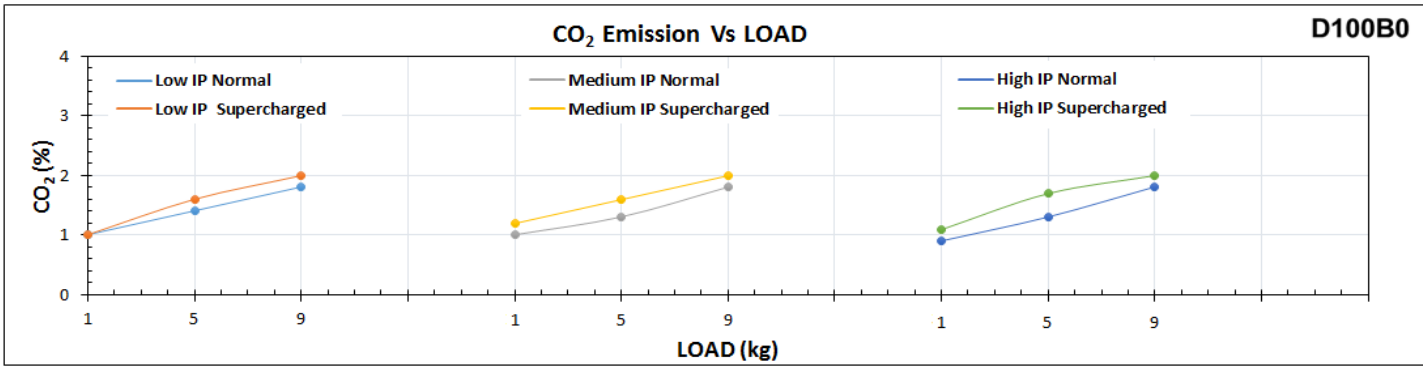

Fig. 5.5.1 $\mathrm{CO}_{2}$ Emission Vs Load graph for D100B0

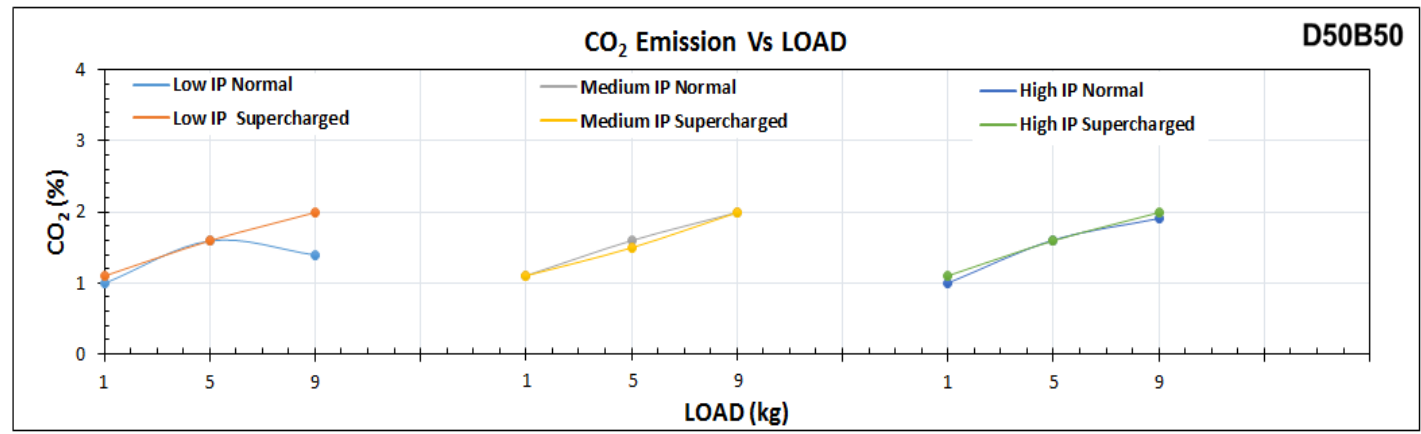

Fig. 5.5.2 $\mathrm{CO}_{2}$ Emission Vs Load graph for D50B50

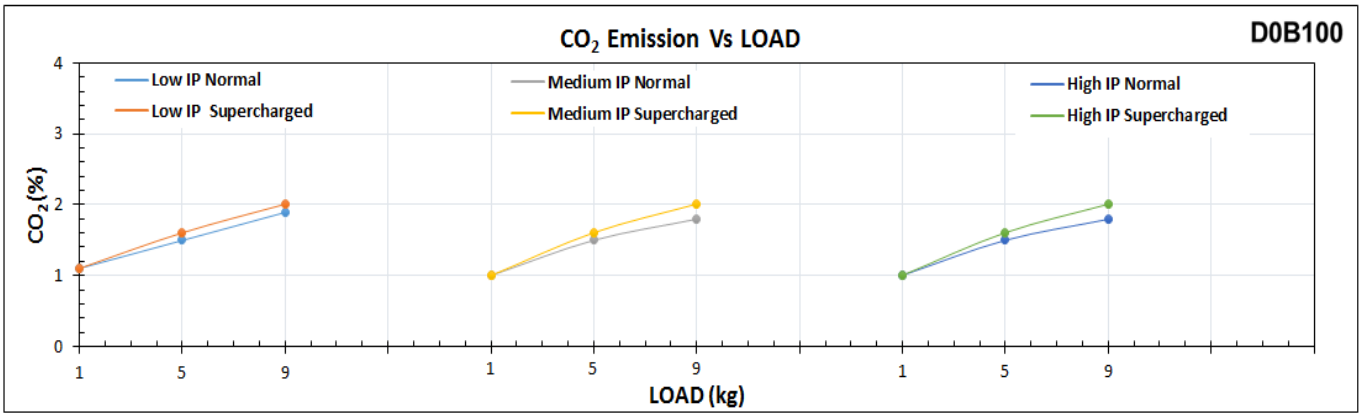

Fig. 5.5.3 $\mathrm{CO}_{2}$ Emission Vs Load graph for D0B100

The variation of Carbon dioxide $\left(\mathrm{CO}_{2}\right)$ emission with different load of the engine for all fuels (D100B0, D50B50, D0B100) of the engine normal \& supercharging condition at different injection pressure is shown in figure as above. Carbon dioxide $\left(\mathrm{CO}_{2}\right)$ emission increased with increase in load on the engine for both condition of the engine for all fuels. In D100B0 $\mathrm{CO}_{2}$ emission is low in normal condition of engine compare to supercharging. While in D50B50 fuel no significant change in $\mathrm{CO}_{2}$ emission in both normal \& supercharging condition. When in $\mathrm{D} 0 \mathrm{~B} 100$ fuel low $\mathrm{CO}_{2}$ emission in engine normal condition compare to supercharging. It was observed that there was no significant difference between engine normal \& supercharging condition with all injection pressure comparatively.

\subsection{NOx Emission:}

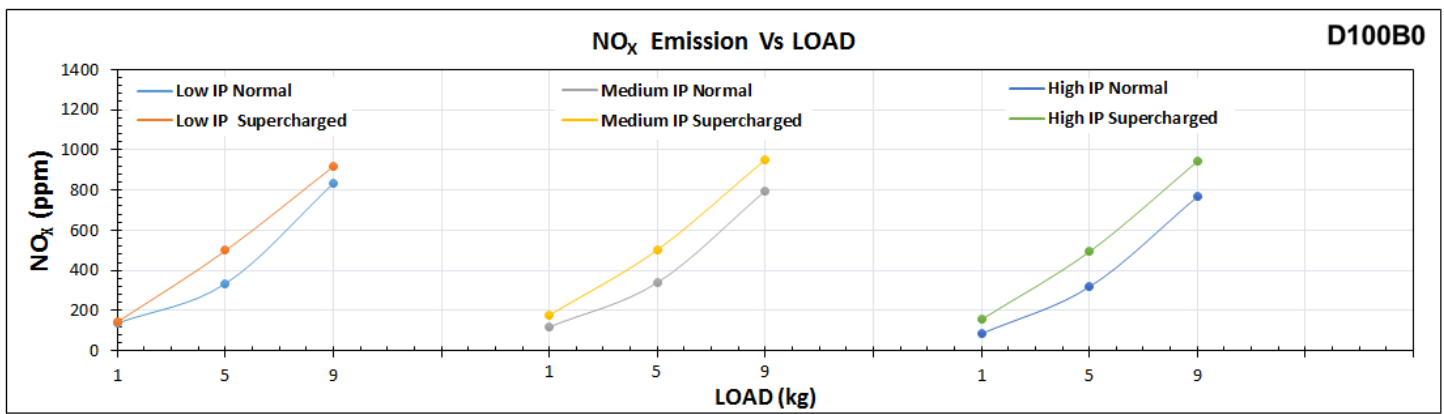

Fig.5.6.1 NOx Emission Vs Load graph for D100B0 
The NOx emission of diesel D100B0 are plotted in the graph as shown in fig.5.6.1. The graph is plotted between $\mathrm{NO}_{\mathrm{X}}$ emission and at varying fuel injection point for the fuel injection pressure of low, medium \& high. NOx emission increased with increase in load on the engine for both condition of the engine normal \& supercharged. From graph it is cleared that in engine normal condition NOx emission is low than supercharging.

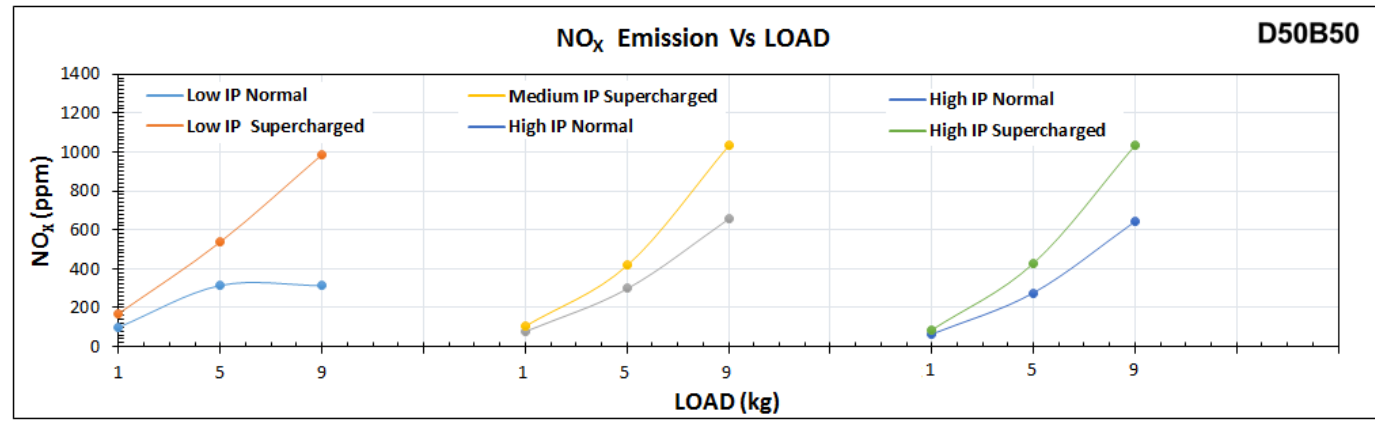

Fig. 5.6.2 NOx Emission Vs Load graph for D50B50

The variation of NOx emission with different load of the engine for fuel D50B50 of the engine normal $\&$ supercharging condition at different injection pressure is shown in figure 5.6.2. NOx emission increased with increase in load on the engine for both condition of the engine for all fuels. From graph it is cleared that in engine normal condition NOx emission is low than supercharging. With the used of D50B50 fuel at the engine normal condition give lower emission of NOx.

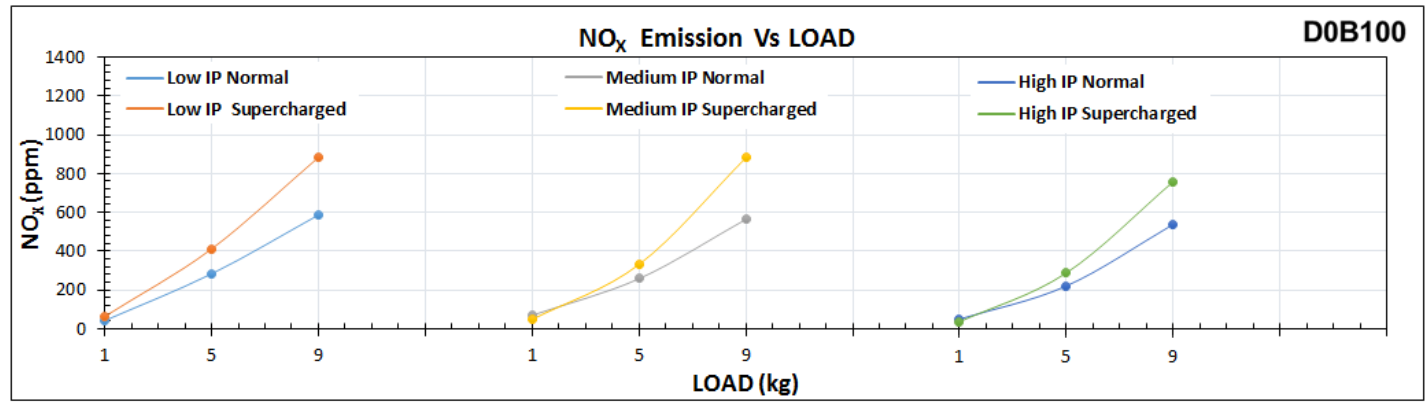

Fig.5.6.3 NOx Emission Vs Load graph for D0B100

The variation of NOx emission with different load of the engine for fuel D0B100 of the engine normal $\&$ supercharging condition at different injection pressure is shown in figure 5.6.3. NOx emission increased with increase in load on the engine for both condition of the engine for all fuels. From graph it is cleared that in engine normal condition NOx emission is low than supercharging condition. With the used of D0B100 fuel at the engine normal condition give lower emission of NOx.

\section{Conclusion}

From the engine emission characteristic was studied, it can be concluded that

The variation of $\mathrm{CO}, \mathrm{HC}, \mathrm{CO}_{2}$ and $\mathrm{NOx}$ emission with different load of the engine at different injection pressure for fuel D0B100 (Jatropha bio diesel), D50B50 (Blended Jatropha) \& D0B100 (Jatropha biodiesel) of the engine normal \& supercharging condition is studied \& concluded.

- With supercharging condition Jatropha biodiesel D0B100 have considerable lesser Emission of $\mathrm{HC}_{2} \mathrm{CO}_{2}$, $\mathrm{NO}_{\mathrm{X}}$ as compared to D50B50.

- D50B50 Jatropha blend have lowest CO emission at all loading condition than D0B100 and diesel fuel at the engine supercharging condition.

- D0B100 blend have lowest $\mathrm{CO}_{2}$ emission than all other blend and diesel at all loads at engine normal condition. With the supercharging effect $\mathrm{CO}_{2}$ emission is increased with use of all Jatropha blend.

- HC emission of diesel engine is low with the use of D0B100 fuel at medium injection pressure \& with engine supercharging condition compare to D50B50.

- $\quad \mathrm{NO}_{\mathrm{X}}$ Emission for D0B100 Jatropha biodiesel have lowest $\mathrm{NO}_{\mathrm{X}}$ emission at all varying loads of engine normal condition. With the supercharging effect NOx emission is increased with use of all Jatropha blend than diesel fuel \& same for both blended fuel.

- D0B100 with supercharging condition can be accepted as a suitable fuel for use in standard diesel engines and further studies can be done with certain additives to improve the emission characteristics. 


\section{References}

[1] Berchmans, H. J., \& Hirata, S. (2008). Biodiesel production from crude Jatrophacurcas L. seed oil with a high content of free fatty acids. Bioresource Technology, 99(6), 1716-1721. https://doi.org/10.1016/j.biortech.2007.03.051

[2] Hanumantha Rao, Y. V., Voleti, R. S., Sitarama Raju, A. V., \&Nageswara Reddy, P. (2009). Experimental investigations on Jatropha biodiesel and additive in diesel engine. Indian Journal of Science and Technology, 2(4), 25-31. https://doi.org/10.17485/ijst/2009/v2i4/29426

[3] Jindal, S. (2011). Effect of injection timing on combustion and performance of a direct injection diesel engine running on Jatropha methyl ester. International Journal of Energy and Environment, 2(1), 113-122

[4] Kim, J., Yim, E., Jeon, C., Jung, C., \& Han, B. (2012). Cold performance of various biodiesel fuel blends at low temperature. International Journal of ..., 13(2), 293-300. https://doi.org/10.1007/s12239

[5] Kumar, M. L. S. D., Drakshayani, S., \& Reddy, K. V. K. (2012). Effect of Fuel Injection Pressure on Performance of Single Cylinder Diesel Engine at Different Intake Manifold Inclinations. International Journal of Engineering and Innovative Technology, 2(4), 20-28.

[6] Liaquat, A. M., Masjuki, H. H., Kalam, M. A., Varman, M., \&Hazrat, M. A. (2012). Experimental analysis on engine performance and emission characteristics using biodiesel obtained from non-edible oil. International Review of Mechanical Engineering, 6(3), $659-665$.

[7] Student, M. T., \& Agricultural, P. (2012). Emission and Performance Characteristics of Jatropha Ethyl Ester Blends with Diesel Fuel in a C. I. Engine, 2(2), 34-47.

[8] Chen, L. Y., Chen, Y. H., Hung, Y. S., Chiang, T. H., \& Tsai, C. H. (2013). Fuel properties and combustion characteristics of Jatropha oil biodiesel-diesel blends. Journal of the Taiwan Institute of Chemical Engineers, 44(2), 214-220. https://doi.org/10.1016/j.jtice.2012.09.011

[9] El-kasaby, M., \&Nemit-allah, M. A. (2013). Experimental investigations of ignition delay period and performance of a diesel engine operated with Jatropha oil biodiesel. Alexandria Engineering Journal, 52(2), 141-149. https://doi.org/10.1016/j.aej.2012.12.006

[10] De, B., \&Panua, R. S. (2014). An experimental study on performance and emission characteristics of vegetable oil blends with diesel in a direct injection variable compression ignition engine. Procedia Engineering, 90, 431-438. https://doi.org/10.1016/j.proeng.2014.11.873

[11] Paul, G., Datta, A., \& Mandal, B. K. (2014). An experimental and numerical investigation of the performance, combustion and emission characteristics of a diesel engine fueled with Jatropha biodiesel. Energy Procedia, 54, $455-467$. https://doi.org/10.1016/j.egypro.2014.07.288

[12] Chaudhari, S. G., Modi, M. A., Patel, T. M., \&Rathod, G. P. (2016). Performance of small capacity compression ignition engine using Jatropha biodiesel blends, 129-133.

[13] Rajneesh Kumar, Anoop Kumar Rathod (2012) Emission and execution attributes of Jatropha ethyl ester mixes with diesel fuel in a c.i. engine.

[14] HannyJohanesBerchmans, Shizuko Hirata (2007) Biodiesel generation from rough Jatrophacurcas L. Seed oil with a high substance of free unsaturated fats.

[15] Jindal, S. (2011). Effect of injection timing on combustion and performance of a direct injection diesel engine running on Jatropha methyl ester. International Journal of Energy and Environment, 2(1), 113-122

[16] Modi, M. A., Patel, T. M., \&Rathod, G. P. (2014). Performance and Emission Analysis of Diesel Engine using palm seed oil and diesel blend, 11(2), 29-33.

[17] Patel, K. B., Patel, T. M., \& Patel, S. C. (2013). Parametric Optimization of Single Cylinder Diesel Engine for Pyrolysis Oil and Diesel Blend for Specific Fuel Consumption Using Taguchi Method, 6(1), 83-88.

[18] Prajapati, J. B., Panchal, P. R., \& Patel, T. M. (2014). Performance And Emission Characteristics Of CI Engine Fueled With DieselBiodiesel Blends, 11(3), 114-121.

[19] Prajapati, H. N., Patel, T. M., \&Rathod, G. P. (2014). Emission analysis of biogas premixed charge diesel dual fueled engine, 4(5), 54-60.

[20] Jani, A., Patel, T., \&Rathod, G. (2015). Effect of Varying Load on Performance and Emission of CI Engine Using WPO Diesel Blend, 12(2), 37-44. https://doi.org/10.9790/1684-12253744 